\title{
The Improvement of Responsibility System of Grassroots Party Construction Under the Situation of Strictly Administering the Party
}

\author{
Linfeng $\mathrm{Wu}$
}

\author{
China National Institute of Standardization, Beijing 100191, China
}

\begin{abstract}
The sixth plenary session of the eighth central committee of the communist party of China has made great efforts to strengthen the party's construction, it insisted on combining thought and system in building the Party. Administering the Party by system is to rule the party according to the rule of law, and the implementation of the system also relies on the construction of the party responsibility system. This paper analyzes the current trend of China's comprehensive and strict rule of the party, combining with the characteristics of the Party organizations of scientific research institutes, and explores some of the challenges existing in the current system of party building responsibility. In view of these problems, the concrete measures of optimizing the responsibility system of party building in scientific research institutes are given. These measures also have some reference significance for the optimization of other party responsibility system.
\end{abstract}

Keywords: strictly administering the party; party construction; responsibility system; improvement.

\section{全面从严治党形势下基层党建责任体系的优化完善}

\author{
吴林峰 \\ 中国标准化研究院, 北京 中国
}

摘要: 党的十八届六中全会专题研究了全面从严治党的重大主题, 提出要加强党的建设, 坚 持思想建党和制度治党的紧密结合。制度治党就是要按照法律法规治党, 而制度的落实还需 要依靠党建责任体系的构建。本文分析了当前一段时间我国全面从严治党的大趋势, 结合科 研院所党组织的自身特点, 探讨了目前党建责任体系存在的若干挑战。针对这些难题, 给出 了优化科研院所党建责任体系的具体措施。这些措施对其他党建责任体系的优化也有一定的 参考借鉴价值。

关键词: 从严治党; 党建; 责任体系; 优化

\section{1. 前言}

从习近平总书记 2012 年 11 月在党的十八大中外记者见面会提到的 “打铁还需自身硬” ，到 2014 年党的群众路线教育实践活动总结大会上提出的新形势下坚持从严治党的 “八点要求” [1]。从 2015 年 3 月十二届人大三次会议上海代表团审议时, 习书记指出的 “全面从严治党, 是我们党在新形势下进行具有许多新的历史特点的伟大斗争的根本保证”再到从严治党的“十 八警句” [2]。不难看出, 党的十八大以来, 以习近平同志为核心的新一代领导集体高度重视, 并且全面推进从严治党这项伟大工程, 已经逐步形成了一套较为完备的思想体系, 将从严治 党理论推向了新高度，反映了当前对广大党员同志严格要求的大势所趋。

党的十八届六中全会专题研究了全面从严治党的重大主题, 并审议通过了两个重要文件, 即

《关于新形势下党内政治生活的若干准则》与《中国共产党党内监督条例》。坚定推进全面 从严治党, 加强党的建设, 坚持思想建党和制度治党相结合。制度治党要求依法依规治党, 然而制度更好的贯彻落实则需要党建责任体系的构建、优化和完善, 需要进一步改革创新、 明确责任。党的十八届中央委员会第三次全体会议提出, 落实党风廉政建设责任制, 党委要 负主体责任, 纪委要负监督责任, 制定实施切实可行的责任追究制度。此外, 从党的十九大 
报告中也同样反映出, 我党要把从严治党要作为是一个长期性的问题来抓。可见, 在新时期、 新的形势下, 强化责任意识, 加强党建责任体系优化对推进从严治党、构建新型国家治理体 系具有非常深远的意义。

\section{2. 全面从严治党是大势所趋}

2. 1. 全面从严治是历史的选择

多年来, 中国共产党一致强调, 如果不坚持从严治党, 党员、干部很容易经不起考验, 以权 谋私, 损害国家和人民利益, 破坏党群关系, 败坏党的声誉。如果容忍党内腐败, 势必使整 个党蜕变和衰败。为了使党的各级组织、广大党员, 特别是党员领导干部经得起执政和改革 开放的考验, 保持党的先进性, 把党建设成为领导中国特色社会主义事业的坚强核心, 必须 要坚持从严治党的方针。

中央文件中首次明确 “从严治党” 的提法是始于 1985 年, 是在中央整党工作指导委员会发出 的《关于农村整党工作部署的通知》中, 提出 “要从严治党, 坚决反对那种讲面子不讲真理, 讲人情不讲原则, 讲派性不惜牺牲党性的腐朽作风”。

此后, 在党的十三大至十八大报告中都强调了加强党的建设、坚持从严治党的要求。[3]其中, 党的十五大对从严治党提出五方面具体要求。党的十八大还提出全面加强党建的八项重要任 务, 并特别针对政治纪律松解、政令不畅等情况, 提出要严明党的纪律, 自觉维护党的集中 统一。[4]

2. 2. 全面从严治党新高度

全面从严治党成为十八大以来党中央抓党建的鲜明主题和特色, 以前所未有的力度、强度推 进全面从严治党, 坚持思想建党和制度治党相结合。理论水平上也有了新的高度, 形成了从 严治党的十八警句, 从六个方面非常生动、形象的把从严治党这个要求向前推进了一大步, 提出了更加明确的要求, 也更便于实施和落实。

2017 年 7 月 26 日, 习近平总书记又在省部级主要领导干部专题研讨班上强调, “全党要坚 持问题导向, 保持战略定力, 推动全面从严治党向纵深发展”, 把全面从严治党搞得更科学、 更严密和有效。

至此, 全面从严治党理论不断丰富和发展, 已经达到了理论与实践紧密结合的新高度。

2.3. 全面从严治党新形式

为了贯彻落实总书记关于从严治党的要求, 以及 “标准决定质量” 的指示精神, 不断提升国 家标准委机关党建科学化水平, 进一步推进全面从严治党及党建责任体系优化, 2016 年, 国 家标准委党组秉承了标准化协调、规范、高效的原理, 发挥标准化简便易行、可持续改进的 优势, 利用其可复制、可推广的特性, 结合机关党建实际, 组织编制并发布了《国家标准化 管理委员会机关全面从严治党标准体系》 [5]（P1-4），对党组工作、机关党委工作、机关纪 委工作、党支部工作、党员管理、机关党建考核从标准化的角度进行了规范, 受到中央国家 机关工委常务副书记李智勇同志的充分肯定。创新性的利用标准化的手段和思路对党建、党 管、考核等工作进行了规范, 这体现了当前对从严治党、构建新型党建责任体系方式的创新 与开拓。

综上可见, 全面从严治党已经是大势所趋。在这个大形势下, 基层党建工作顺应需求, 开展 地如火如茶。然而, 快速发展的同时可能也会存在一些挑战。

\section{3. 基层党建工作存在的挑战}

目前, 我院紧紧围绕深化全面从严治党、以严治院的总要求, 坚持问题导向, 夯实工作基础, 突出监督重点, 在全面从严治党的大环境下, 已经构建出一条较为完备的、适合科研院所党 组织管理和发展的党建责任体系。然而, 据调研, 大多数科研院所虽然也大都建立了一套党 建责任管理制度及管理规定, 但是由于信息化、科学化、理论创新、标准化应用的快速发展 
等原因, 党建责任体系在一些科研机构中还有进一步优化和完善的地方。现阶段, 基层科研 院所党建工作还存在以下三个方面的挑战。

3. 1. 责任体系理解难到位

信息技术高度发达, 党建科学化、理论创新、技术融合等的快速发展, 标准化应用领域也不 断拓展的背景下, 党建责任体系相关的观念、理论和方法发展速度异常迅猛, 党建责任体系 理论也不断发展和完善, 如何紧跟步伐, 掌握最新理论是一个挑战。由于受市场化大环境的 影响, 又考虑到员工现实较大的生活压力, 基层科研院所为了留住人才、加快发展, 不得不 争取更多科研项目与合作, 基层党员同志主动学习最新理论政策的积极性不够, 加之繁重的 科研任务压力, 常常没有更多精力参与党建责任体系相关新理论、新思想、新方法的学习、 研究和应用。在新形势下, 基层科研院所党员同志往往很难对新型党建责任体系理解非常深 刻。

3. 2. 责任体系更新不及时

基层科研院所由于受其职能定位的影响, 一般通过项目追踪、细化清单、规范流程、纪检监 察等方面, 进行层层把关, 初步构建起基层科研院所党建责任体系, 切实推动了党建工作责 任在基层的落地生根。然而通过调研, 发现党建机构在科研院所不受重视, 党建活动受到经 费及反腐大环境的限制和影响, 畏手畏脚、活动形式单一、党员群众参与积极性不高的现象 普遍存在。归根到底, 这些是由于基层党建责任体系过于陈旧、更新不及时、责任体系不完 善, 群众意见反馈渠道不畅通造成的, 致使党建活动组织不力、缺乏创新和活力。

3. 3. 责任还需进一步明确

“工匠精神” 最近被李克强总理在多个场合采用。“工匠精神” 其实自古就有典型案例。儒 家经典《礼记》记载: “物勒工名, 以考其诚, 工有不当, 必行其罪, 以究其情。”此外, 陕西兵马俑坑出土的上万件青铜兵器中, 每一件兵器上都刻有各级管理者和制作者的姓名, 且兵器工艺的精准度误差仅为 0.8 至 0.02 毫米。中国古代工匠实名制除在产品上要刻上工匠 名字外, 还曾专门设置了负责质量管理的官员职位, 以便随时监管产品质量。[6]可见, 中国 自古就有明确的责任制。然而当前从严治党的大环境下，基层科研院所还存在 “各人自扫门 前雪” 的现象, 怕担责任。作为一个研究机构整体, 有的机构缺乏团队意识和整体意识, 工 作推诿现象还存在, 对于边缘性问题, 制度没有明确规定到的问题存在 “多一事不如少一事” 的现象还时有发生。

\section{4. 基层党建责任体系优化措施}

针对基层科研院所在全面从严治党环境下, 党建责任体系普遍存在的一些挑战和需要完善的 地方, 结合科研院所自身特点及实践经验, 笔者提出以下几点有利于科研院所党建责任体系 优化的建议措施。

4. 1. 促进融合, 明确责任

基层科研院所离不开科研任务的完成, 在保障科研任务的同时, 也要注重培养党员团队意识、 责任意识。我们可以将党建责任体系与科研责任相结合，同时，充分发挥科研院所技术攻关 能力强、能吃苦、甘于奉献的精神, 将党建责任工作的落实与科研院所业务工作深度结合, 明确责任, 以使各党支部能够主动地、自觉地融合并落实基层党建责任体系构建的要求。从 科研任务的分解到具体落实, 各党支部能全程参与, 并且充分发挥保障职能作用, 相互促进, 共同发展, 真正实现以科研促党建, 以党建保科研。例如, 我院为了落实从严治党、加强责 任体系的建设要求, 印发了《中国标准化研究院党委关于开展落实全面从严治党要求、履行 党风廉洁建设责任情况专项检查的通知》（中标院党发(2017) 30 号），要求全院进行自查。 编制了《中国标准化研究院党风廉洁建设责任清单表》, 将责任进行了明确。

4. 2. 加大扶持, 鼓励创新

增加经费投入，共同健全和优化党建责任体系，从而明确落实责任。可以设立相应奖金、奖 项激励机制, 在科研院所充分发挥群策群力, 集聚群众智慧, 鼓励党建方式、方法和应用的 
创新, 共谋党群建设。例如我院结合科研院所的特点, 提出了纪检监察与内部审计相结合的 监督新思路, 及时发现科研业务工作中的问题, 起到了较好的内部监督和督导的作用。

4. 3. 修订制度，适应发展

借鉴我国古代优秀传统, 还需要进一步明确责任, 随着时代发展, 也要及时对制度、管理规 定不断更新完善。国家标准委拓展标准应用领域, 创新性地将标准应用到党建工作上来。我 们也可以参照对标准进行修订的模式, 对党建制度、管理体系定期组织复审、修订, 不断健 全和优化研究院所业务管理责任体系, 这也是对党建责任体系的一种优化。

\section{5. 结语}

从严治党的纵深发展、科学发展、落地实施, 是以习近平同志为核心的新一代领导集体花大 气力来抓的大问题, 在这个大形势下, 科研院所党组织应该结合其自身特点和优势, 开拓创 新、锐意进取。及时优化完善其党建责任体系, 使其党建责任体系向着科学化、实用化方向 不断迈进，应该为做好支撑，推进国家治理体系和治理能力现代化做出应有的贡献。

\section{Acknowledgements}

This research was financially supported by research of national standardization strategic positioning, target and key tasks (number: 572017B-5361-2017), the compilation of the annual report of China standardization ( number: 572014B-3898), and the president foundation of CNIS (number: 572016Y-4675).

\section{References}

[1]. Xi Jinping. Xi Jinping's Speech on The Education Practice Activities of Party's Mass Line at Summary Conference, 2014-10-08.

[2]. Cui Dong. Xi Jinping's Eighteen Sentences on Strengthen Party Discipline. People's Daily, 2016-07-01, Version 09.

[3]. Jiang Yongbin, Qu Peng. Comprehensively Strength Party Discipline Is Always on the Road, Paper of China Discipline Inspection And Supervision, 2017-08-07.

[4]. Ye Duchu and Lu Xianfu. Party's Construction Dictionary. Beijing: Party School of The Central Committee of Cpc Press, 2009.

[5]. Jia Ke, Li Xuanqing, Zheng Jian Etc. Standard System of Comprehensively Strengthen Party Discipline In National Standardization Management Committee. Beijing: China Zhijian Publishing House Press, Standards Press of China, 2017.

[6]. Chang Shuxiang. Ancient Craftsman System: the Utensil Must Be Engraved on The Name of the Maker to Facilitate the Inspection of Product Quality By the Manager, Luoyang Daily, 2016-11-8. 